\title{
A RESPIRATION INCUBATOR FOR THE STUDY OF THE ENERGY METABOLISM OF INFANTS*
}

\author{
JOHN R. MURLIN, Ph.D. \\ NEW YORK
}

For the study of the metabolism of infants, especially new-born or premature infants, it is important to have perfect control of the temperature to which the child is exposed. Preliminary work on animals with a respiration chamber surrounded by water, the latter kept warm by means of a gas-flame placed underneath, convinced me that a more exact control was necessary before observations on the infant could be undertaken. In casting about for a satisfactory type of thermoregulator, the Freas oven came to mind and after conference with the inventor (Prof. Thomas B. Freas, Dept. of Chemistry, Columbia University) as to the feasibility of the application of his regulator to the purposes in hand, plans were agreed on for the construction of an electric incubator which would be suitable for the introduction of a respiration chamber large enough to contain an infant one year of age. Dr. Freas has placed the laboratory under special obligations for the interest he has shown in the execution of these plans.

This particular incubator measures 60 by 82 by $115 \mathrm{~cm}$. outside and 46 by 48 by $100 \mathrm{~cm}$. inside. It rests on a special iron stand provided with it, $85 \mathrm{~cm}$. above the floor and makes a good appearance as a piece of laboratory or hospital furniture (Figs. 1 and 2).

The regular plan of construction of the Freas air thermostat ${ }^{2}$ was departed from in only a few particulars. For example, it was necessary to have a considerable number of openings through the wall for the passage of the ventilating-pipes and cooling-coil, the introduction of thermometers, the connection of the oxygen regulator, etc. The range of temperature was fixed at from 20 to $50 \mathrm{C}$., the capacity of the heater being limited to 200 watts. The motor for driving the stirring-fan (Fig. 5, F) which is provided with the incubator was mounted on a large steel spring so that the vibrations should be damped out to some extent. The glass doors were made as large as the front

\footnotetext{
* From the Physiological Laboratory of the Cornell University Medical College, New York City.

1. Freas, Thomas Bruce: A Study of Thermostats, Dissertation, University of Chicago, 1911.
} 
end, thus permitting plenty of light to enter and were provided with strips of felt so as to make the closure practically air-tight.

\section{THE RESPIRATION CHAMBER}

The chamber measures 30 by 32 by $76 \mathrm{~cm}$. inside. It was made of 14-ounce tinned copper, strongly lock-jointed and soldered, and was rimmed at the front end by a heavy brass casting. Another casting of the same dimensions was made as a frame for the glass head or door of the chamber. The glass is held in place by litharge cement covered with heavy wax and a coat of white-lead. A heavy rubber gasket is

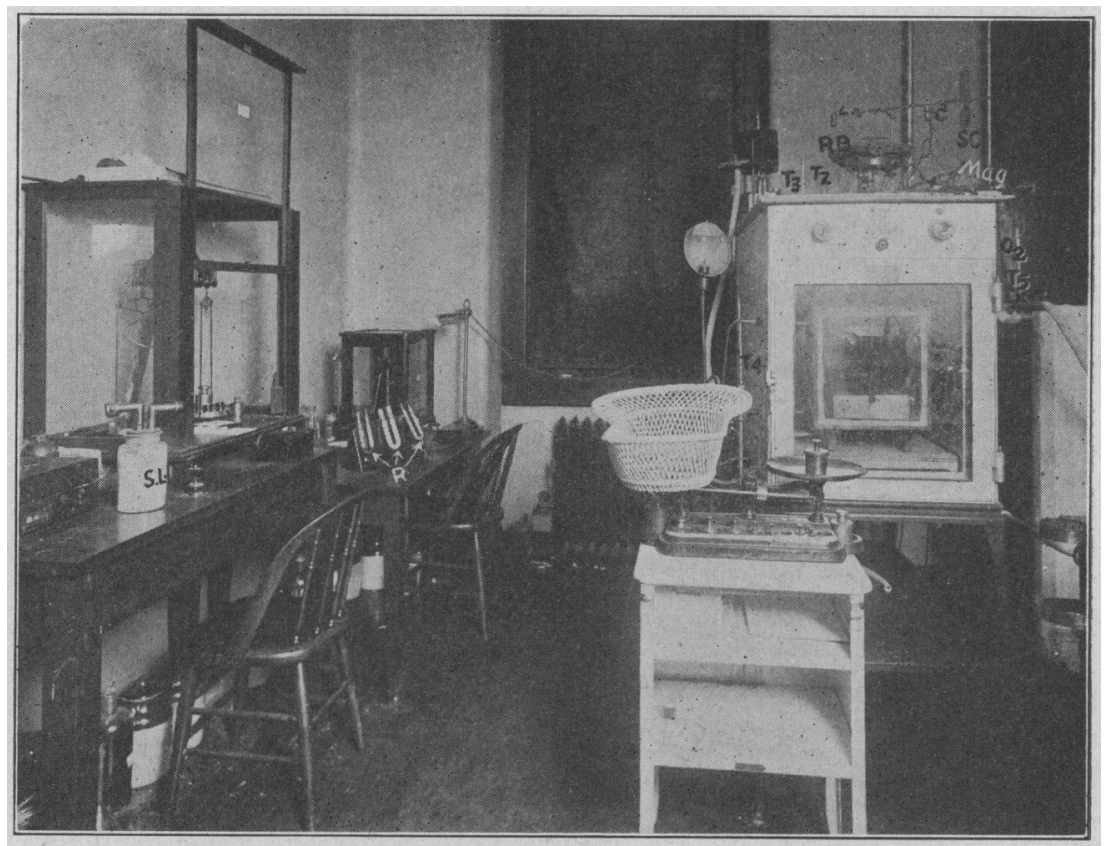

Fig. 1.-General view of room in Bellevue Hospital containing respiration incubator (Eimer and Amend) set up ready for use. The inner chamber is shown through the glass doors of the incubator. Inside the chamber the bed is seen. The balances on the left of the room are used in weighing the absorbers. The balance in the middle of the room (sensitive to $1 \mathrm{gm}$.) is used in weighing the infant. Further description in the text.

cemented to the brass rim, and a perfectly air-tight closure of the chamber is secured by clamping the frame of the head firmly against this gasket by means of twelve L-shaped steel bolts, which engage the back side of the brass rim (Figs. 2 and 3 ). The chamber is mounted on wooden runners and is strongly reinforced by means of three galvanized iron ribs girthing it at equal intervals from front to back. 
Pressure changes inside or outside the chamber, therefore, do not alter its volume.

Since the inculbator measures 46 by 48 by $100 \mathrm{~cm}$. inside, a space $7.5 \mathrm{~cm}$. wide is left on all sides of the chamber. The air in this space is kept in motion by a fan (Figs. 4 and 5 ).

\section{IENTILATION AND MEASUREMENT OF RESPIRATORY EXCIIANGE}

The ventilation of the respiration chamber is accomplished by means of a Benedict "universal respiration apparatus," connected to it by means of wide rubber tubing and $1 / 2$-inch brass pipes. The brass pipes are screwed into strong brass bushings soldered to the copper

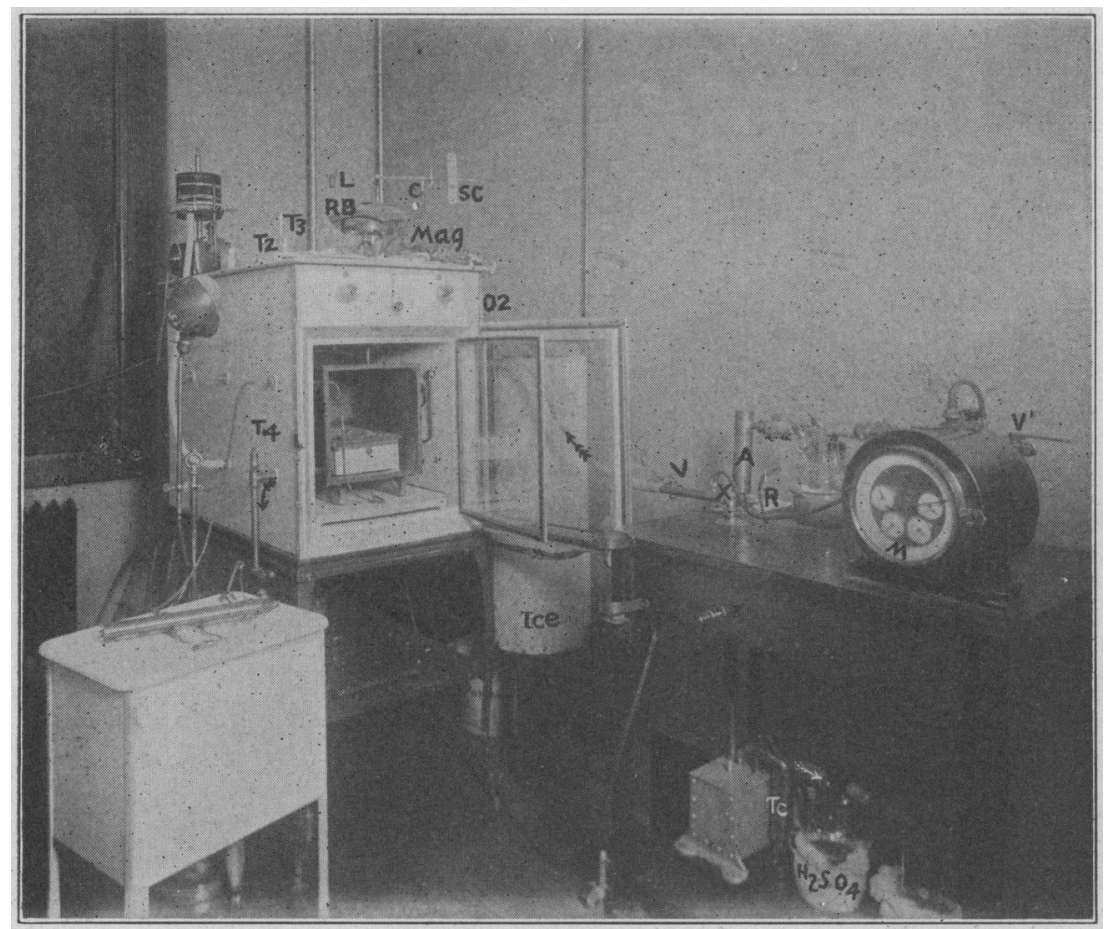

Fig. 2.-Another view of the same room. The absorber table is seen at the right. The glass doors are open and the glass head of the inner chamber is lying on the shelf below the incubator. The stethoscope tubes may be seen lying on the nurse's table and the bell of the stethoscope inside the incubator. Further description in the text.

wall. The inlet pipe enters at the upper back corner of the chamber on the right side and the outlet is connected with the lower front corner on the left. Thermometers are admitted to the inlet and outlet pipes by means of $T$ joints (Fig. 3, T4). The arrows in Figure 2 show the direction of the air current.

2. Benedict, F. G.: Am. Jour. Physiol., 1909, xxiv, p. 345; Deutsch. Arch. f. klin. Med., 1912, cvii, 156; Am. Jour. Dis. Child., 1914, viii, 1. 
The Absorber System.-The Benedict apparatus was so constructed for use with the incubator that by turning valves ( $V$ and $V^{\prime}$, Fig. 2) the absorbers could be quickly changed after stopping the blower, without the loss of more than 20 c.c. of air. $\dagger$ Each set of absorbers consists of two soda-lime jars for absorption of carbon dioxid and a sulphuric acid absorber for catching the water lost from the soda-lime. Each of these absorbers is small enough to be weighed (separately) on a Sartorius balance sensitive to $0.001 \mathrm{gm}$. The soda-lime absorbers are made on the plan (Fig. 1, S. L.) adopted for the absorbers used with the Sage calorimeter in Bellevue Hospital. ${ }^{3}$ The sulphuric acid

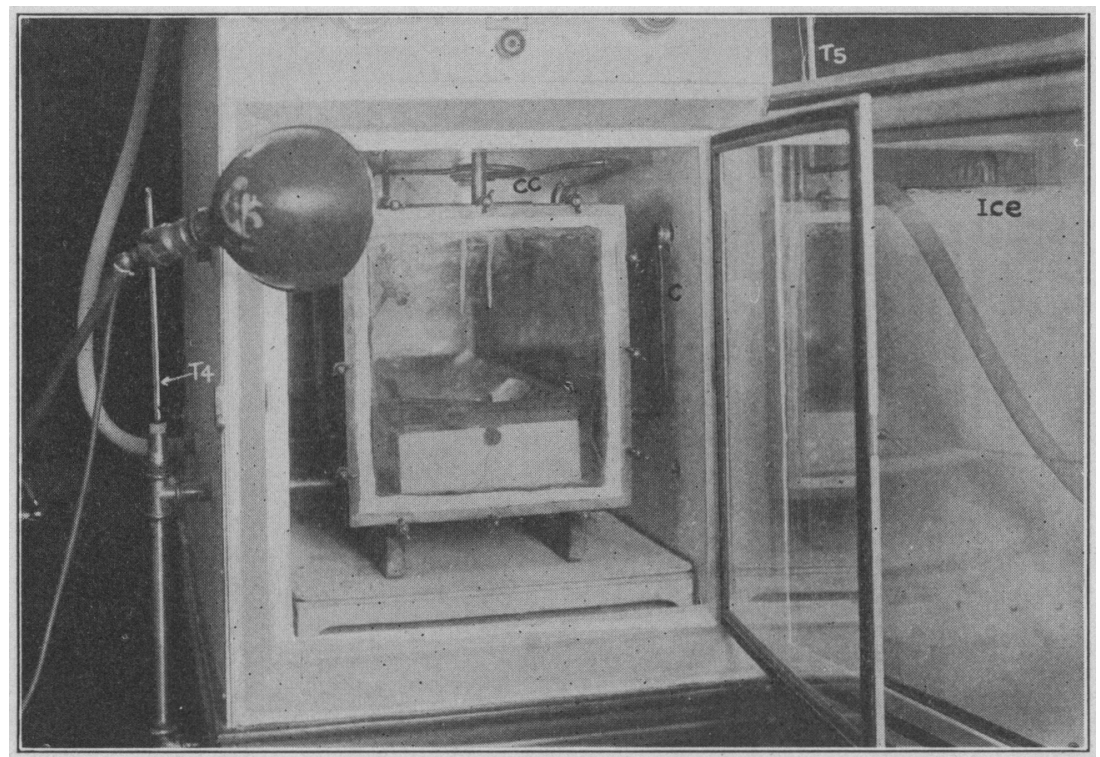

Fig. 3.-A near view of the interior of the incubator showing the cooling coil, c.c.

absorber is the gas washing-bottle designed by Williams ${ }^{4}$ for use with the animal calorimeter in this laboratory. Immediately following the sulphuric acid absorber is a brass tower containing sponges kept moist with very dilute sodium hydroxid solution, which serves the double purpose of imparting a slight amount of moisture to the air and of arresting any traces of acid fumes which may come from the dryingbottle.

Since the water given off from the lungs of the child does not enter into the computation of the heat production by the indirect method

† Since this was written the table has been reconstructed so two sets of absorbers can be connected at once and the change from one to the other accomplished with a single lever operating both valves.

3. Lusk, Soderstrom and Riche: Arch. Int. Med., to appear soon.

4. Williams: Jour. Biol. Chem., 1912, xii, 323. 
(except as this water may affect the volume of the oxygen admitted), the absorbers used in the collection of this water are not weighed. They consist of two Williams bottles placed in series after the blower on the under part of the absorber table (Fig. 2, $\mathrm{H}_{2} \mathrm{SO}_{4}$ ). A brass trap (Fig. 2, Tr.), of a capacity about equal to the amount of the sulphuric acid contained in the first Williams bottle, is introduced for the safety of the blower. A bicycle coaster brake on the large pulley of the blower makes it impossible to turn the blower the wrong way; but the trap would catch any acid which might be drawn back by sudden blockade of the air-circuit at any point.

The Residual System.-The measurement of the oxygen absorbed by the child is based on the general proposition that oxygen be admitted to the air-circuit just as rapidly as it is used. This presupposes that the respiratory products should be absorbed and removed from the air as rapidly as they are produced. The efficiency of the absorbers is such that as far as the welfare of the child is concerned the ventilation is perfect. Neither carbon dioxid nor water vapor can accumulate to any appreciable extent. But an absolutely perfect adjustment of the rate of ventilation so as to leave the composition of the air exactly the same at the end of a period as at the beginning is impossible, especially if the child should cry or void urine near the end of the period. Since the admission of oxygen is regulated by the total volume of the air, (see below) and since this volume will vary with the amount of water vapor in it as well as with the temperature and barometric pressure, it is necessary to know the composition of the air at the close as well as at the beginning of a period. The analysis is carried out by diverting a measured sample of air from the main circuit, causing it to flow through a special set of absorbers and returning it to the system without loss of anything more than the small quantities of carbon dioxid and water contained in it. These analyses are called the residuals because they give information as to the amounts of the various gases residual in the air at definite moments.

A small copper pipe is tapped into the main circuit on the positive side of the blower (Fig. 2, $R$ ) and is led upward through the top of the table. By turning a stop-cock at the base of this pipe a small fraction of the total air current can be drawn off. The residual absorbers consisting of three $U$ tubes (Fig. 1, R) (the first containing sulphuric acid and pumice stone, the second finely granular soda-lime and the third sulphuric acid and pumice stone again) ${ }^{5}$ are connected to this small pipe and the air having passed through them is conveyed to the meter (Fig. 2, M) where it is measured, thence through a drying-

5. Cf. Benedict and Carpenter: Carnegie Institution of Washington, Publ. 123, p. 73. 
tower ${ }^{6}$ (the meter contains water) and back to a point (Fig. 2, x) in the main system where the pressure is low.

The $U$ tubes are weighed to the fourth decimal place before and after drawing off the sample. When the amounts of water vapor and carbon dioxid in this measured sample (usually 5 liters) are known, the total amounts in the entire system are readily calculated. By a series of corrections which will be better understood after the method of conducting an alcohol check is explained, the amount of oxygen residual in the air at the time the air sample is taken can also be computed.

The Oxygen System.-Oxygen is admitted into the ingoing air so that it may be thoroughly diffused into the chamber. The amount admitted is regulated by the method first described by Benedict and Carpenter ${ }^{5}$ and as slightly modified by Williams ${ }^{4}$ in his construction of the animal calorimeter. 'The essential parts of this arrangement consist of a rubber bag or spirometer which serves as a tension equalizer and volume indicator at the same time (Figs. 1 and $2, R B$ ) and a magnet $(M a g$.$) , which, when actuated, releases pressure on a$ rubber tube leading from the oxygen cylinder $\left(\mathrm{O}_{2}\right)$. The rubber bag communicates with the respiration chamber by means of a brass pipe, and a valve in this pipe permits the bag to be shut off from the chamber. The oxygen cylinder ${ }^{i}$ while in use is suspended from a strong hook at the right side of the apparatus conveniently near the magnet. The magnet is connected through a resistance board carrying three lamps and through the mercury cups $(C)$, situated on the horizontal arm above the magnet, with the house current. A lever $(L)$ $38 \mathrm{~cm}$. long is pivoted above the bag and is so counterpoised that it rests lightly on the bag by means of a broad metal disk. The arm ends at the right in a point which traverses a scale $(S c)$. It carries contact points which dip into the mercury as the lever descends. As the oxygen in the air of the circuit is used up by the child the bag collapses until the lever makes contact with the mercury (sparking is prevented by means of a condenser not shown in the figures). This actuates the magnet and releases pressure on the pure gum tubing leading from the oxygen cylinder. Oxygen thereupon enters the circuit until the volume is increased sufficiently to break the electric circuit, when pressure is again applied to the tubing thereby shutting off the oxygen; and so on.

6. The drying-tower is not shown in the figure because it stands behind the meter.

7. Purchased from the Consolidated Dental Mfg. Co., New York. These cylinders measure $4 \mathrm{~cm}$. diameter by $33 \mathrm{~cm}$. in length. They will contain about $50 \mathrm{gm}$. of oxygen under a pressure of 100 atmospheres. Together with the reduction valve the cylinder weighs about $1.5 \mathrm{~kg}$. and can be weighed on the Sartorius balance to $0.001 \mathrm{gm}$. 
At the beginning of a period oxygen is let into the system by hand until the pointer of the lever rests at a certain mark on the scale. At the end of the period the system is again filled to exactly the same point. If the volume of the air has not changed (by change of temperature, pressure, or composition of the air) the loss in weight of the cylinder would be the amount of oxygen consumed. Such conditions, however, would be very exceptional; hence all corrections must be made for every period.

Oxygen cannot be let into the system by any such automatic arrangement until the pressure which exists in the cylinder is reduced to a pressure which the rubber tube will withstand. A valve which reduces this pressure to a few pounds per square inch was made for these cylinders by the mechanician of the laboratory, Mr. James Evenden. It is shown in Figure 4.

Switch-Board.-A special switch-board, the end of which can be seen in Figure 6, provides electric outlets for: (1) the heater of the incubator; (2) the fan motor; (3) the motor on the absorber table; (4) the oxygen regulating system, and (5) any extra lamps required for illumination of the balances (Fig. 1), the interior of the incubator (Fig. 3), etc.

The Cooling-System.-The walls of the incubator being constructed of materials having a low coefficient of conductivity, the heat produced by the infant would not be conducted away as rapidly as produced and the temperature inside would rise unless the room air were at a very low temperature. To counteract this tendency and to furnish a chilling effect against which the heater of the incubator should operate, a cooling-system was installed. This consists of a coil (Fig. 3, cc) of copper pipe, $1 / 4$ inch inside diameter, making several turns on the two sides and the top of the inner wall of the incubator and carrying a stream of tap-water. At ordinary room temperature and with tapwater coming directly from the mains (that is, not warmed unduly by the house pipes) it is not necessary to chill the stream. It flows, however, through a coil of pipe inside an ice-tank (Figs. 1, 2 and 3), and in very warm weather the water can easily be kept down to the desired temperature by placing ice in contact with the coil. To secure a constant flow the water is given a constant head of pressure by passing it through a flush tank, operated by a ball cock, placed near the ceiling of the room. (This tank is too high to be seen in any of the figures, but the pipes leading to and from it are seen.) After passing through the cooling-system the water is conducted back to the sink.

A thermometer (Figs. 1 and 3, T5) is placed in the stream of water, and a wheel valve is placed near the tank, so that the cooling effect can be regulated to some extent both by the amount of ice and 
by the rate of flow of the water. The thermoregulator of the incubator takes care of the finer regulation. The heater is sufficient to keep the space about the respiration chamber at $27 \mathrm{C}$., even when the water is at $4 \mathrm{C}$. and the rate of flow 400 to 600 c.c. per minute. This would be wasteful of electric current, however, and a water temperature of from 10 to $15 \mathrm{C}$. with a rate of 200 to 300 c.c. of water is more than sufficient to carry away the heat produced by a year-old infant even in very warm weather, unless the infant cries actively. In the latter case the speed of the water can be increased, or more ice can be introduced or

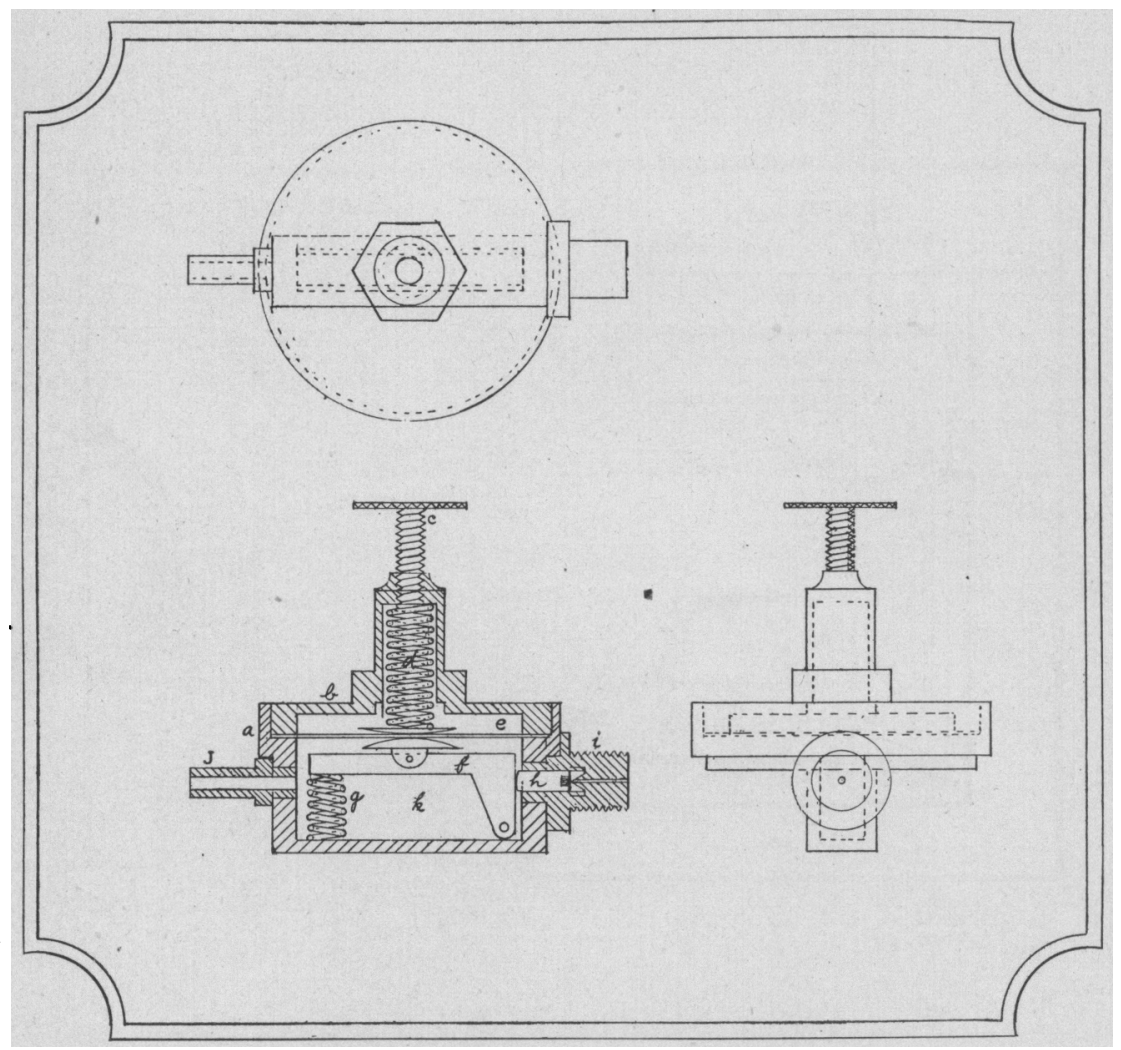

Fig. 4.-Detail of reducing valve used on small oxygen cylinder: $A$, case; $B$, lid of case; $C$, screw to compress spring; $D$, spring to reduce diaphragm; $E$, diaphragm; $F$, lever to close valve; $G$, spring to raise lever; $H$, valve with hard rubber tip to control oxygen; $I$, end to screw into oxygen cylinder; $J$, end for hose, oxygen supply. Oxygen contained in cylinder is held back by valve $H$. By compressing spring $D$ with screw $C$ lever $F$ is lowered, thus allowing valve to come back and permitting oxygen to enter chamber $K$ until the pressure beneath the diaphragm is sufficient to bring it to its original position which shuts off the oxygen again. When the oxygen in chamber $K$ is below the desired pressure the tension of spring $D$ again lowers the lever and repeats the operation. 
the heater can be turned off. With such a cooling effect as just mentioned the temperature outside the chamber falls very quickly, and within a very few minutes also the temperature inside the chamber.

\section{HEAT CONTROLS}

Many control tests were made with the incubator as adapted in this way to the purposes of a respiration apparatus, both empty and with animals, before it was used with infants. Four thermometers are regularly used in the following positions: No. 1 (not shown in

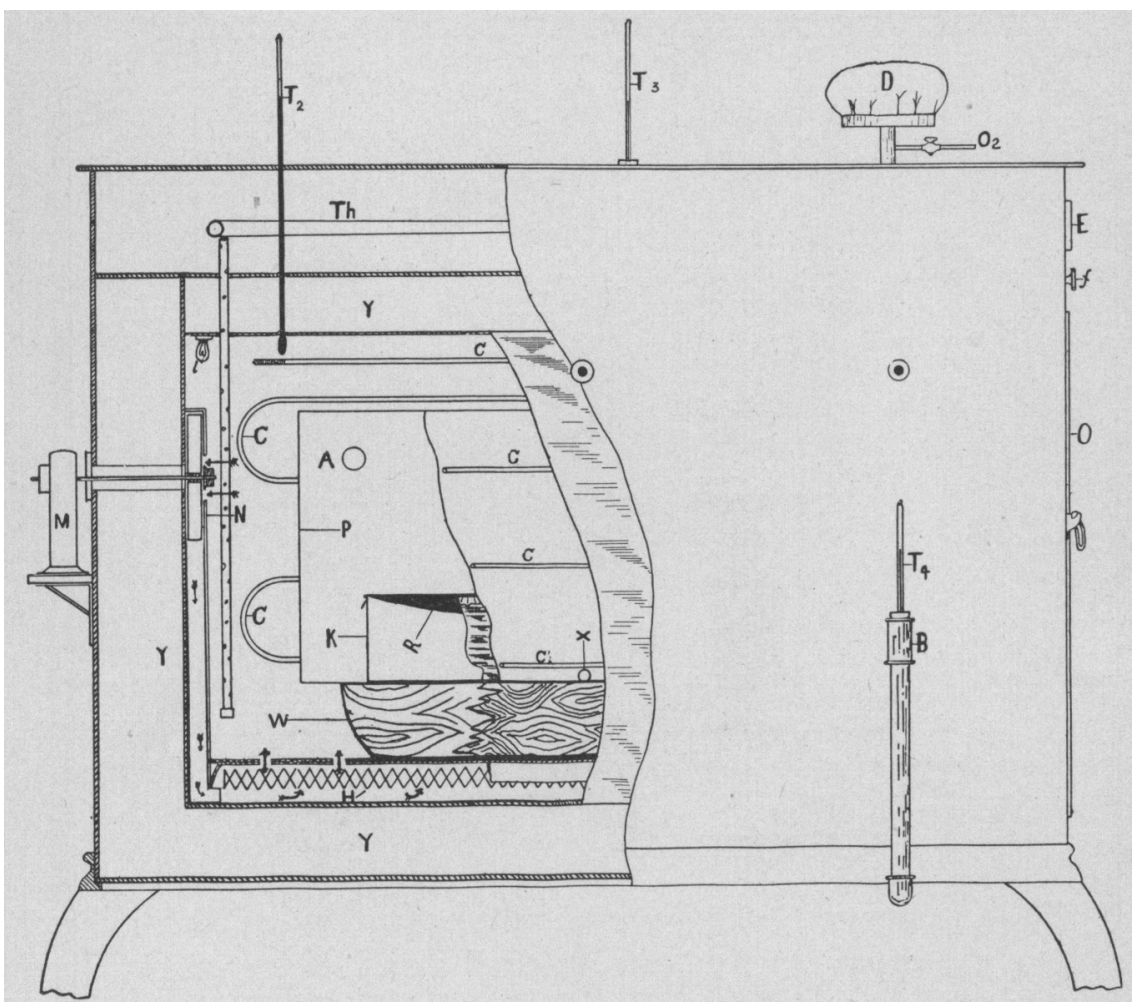

Fig. 5.-Sectional view of the incubator from the side. $Y$, asbestos packed wall ; $H$, heater coil ; $C$, cooling pipes; $P$, copper wall of inner chamber; $A$, point of entrance for air; $B$, exit pipe for air, containing thermometer; $W$, wooden runner which supports copper chamber; $K$, bed inside respiration chamber; $R$, rubber diaphragm; $T h$, thermo regulator; $M$, fan motor; $N$, fan. Arrows show direction of currents which equalize temperature inside the incubator. $D$, rubber bag for regulation of oxygen; $l$, lamp; $f$, control for setting regulator at any desired temperature.

any illustration) in the ingoing air; No. 2 on the top at the rear end of the incubator, the bulb extending into the outer air space; No. 3 ( $T_{3}$, Figs. 1, 2 and 5 ) on top near the center, the bulb extending 1 inch 
into the inner air-space, and No. 4 in the outgoing air. All these thermometers are graduated to tenths of a degree $C$. and can be read to $0.05^{\circ}$. An air thermometer is usually kept on the wall near the absorber table.

Table 1 will serve as an example of the accuracy of the heat control. The subject was a small black dog, $4 \mathrm{~kg}$. in weight, which lay perfectly still the entire hour.

TABle 1.-Heat Control Subject, Small Black Dog

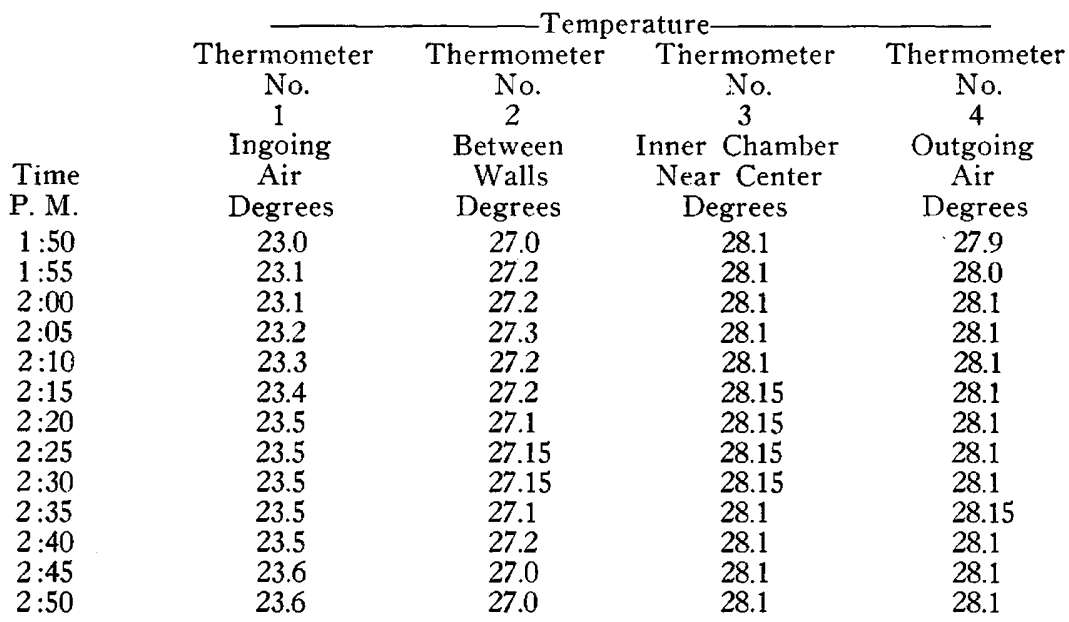

The air temperature rose 0.6 of a degree during this observation and the temperature in the outer air space fluctuated somewhat according as the heat happened to be on or off at the moment of reading; but the temperature inside the inner chamber hardly varied at all during the entire hour.

CONTROL RY COMBUSTION OF ALCOHOL

The accuracy of the entire respiration apparatus has been checked many times in the course of the year and a half during which it has been in use, by combustion of alcohol in the chamber and the determination of the "respiratory quotient" of the flame. In the great majority of these check experiments all corrections have been made; but at times it has been sufficient to measure the oxygen by loss in weight of the cylinder with a correction for argon and the carbon dioxid by gain in weight of the absorbers without further corrections. With the flame burning uniformly the carbon dioxid residual in the circuit often does not change at all from the beginning to the end of a period. The water almost always falls the first period and then remains constant. 
An example of a complete check experiment is given showing the manner of making all corrections. The same corrections and the same methods of calculation are used when the subject is a child.

Dec. 23, 1913. Alcohol check experiment.

Contents of respiration chamber - alcohol lamp and bed.

$\begin{array}{lll}\text { Vol. of air containing } \mathrm{CO}_{2} & 67 & 1 . \\ \text { Vol. of air containing } \mathrm{H}_{2} \mathrm{O} & 66 & 1 . \\ \text { Vol. of air containing } \mathrm{O}_{2} \text { and } \mathrm{N}_{2} & 69 & 1 .\end{array}$

First period from 4:52 to $5: 52$ p. m.

At 4:52 residual analysis.

5 liters air contain $0.0178 \mathrm{gm} . \mathrm{CO}_{2}$ and $0.0136 \mathrm{gm} . \mathrm{H}_{2} \mathrm{O}$

67 liters air contain $0.238 \mathrm{gm} . \mathrm{CO}_{2}(=0.121$ 1.)

66 liters air contain 0.179 gm. $\mathrm{H}_{2} \mathrm{O}(=0.2231$.)

To find residual $\mathrm{O}_{2}$.

Temperature $28.06 \mathrm{C}$; ; barometer $765.1 \mathrm{~mm}$.

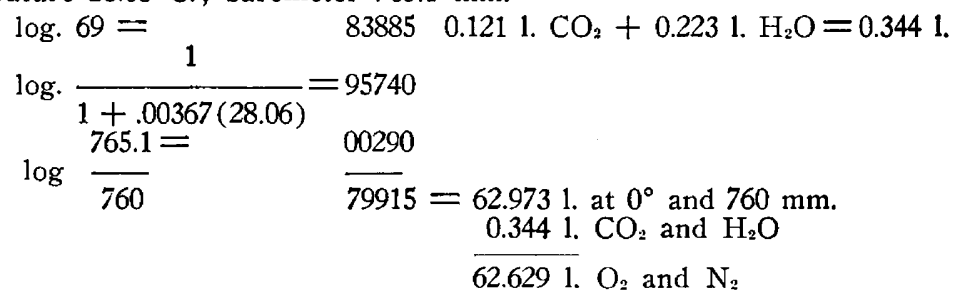

Subtracting four-fifths for $\mathrm{N}_{2} 50.1032$

$$
\overline{12.52581 .} \mathrm{O}_{2}
$$

At 5:52 residual analysis.

5 liters air contain $0.0178 \mathrm{gm} . \mathrm{CO}_{2}$ and $.0136 \mathrm{gm} . \mathrm{H}_{2} \mathrm{O}$

67 liters air contain 0.238 gm. $\mathrm{CO}_{2}(0.121$ l.)

66 liters air contain 0.129 gm. $\mathrm{H}_{2} \mathrm{O}(0.2231$ 1.)

To find residual $\mathrm{O}_{2}$.

Temperature $28.23 \mathrm{C}$; ; barometer $765.3 \mathrm{~mm}$.

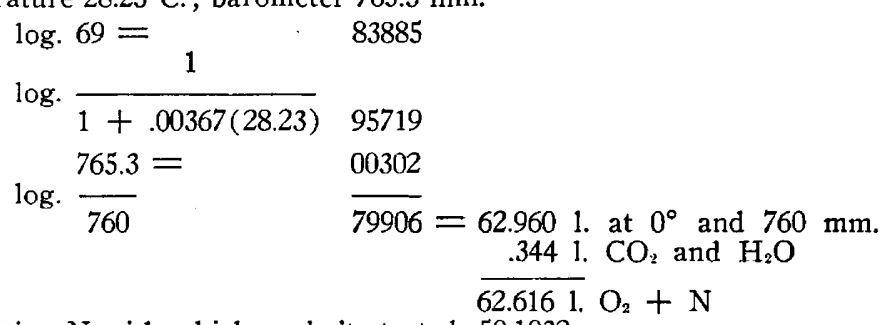

Subtracting N with which exp'm't started, 50.1032

$$
12.51281 . \mathrm{O}_{2}
$$

"Respiratory Exchange" Period 1

Gain in weight of $\mathrm{CO}_{2}$ absorbers $4.850 \mathrm{gm}$.

Loss in weight of $\mathrm{O}_{2}$ cylinder... $5.090 \mathrm{gm}$.

$0.6 \%$ correction for argon $=0.03 \mathrm{gm}$.

Loss in weight due to oxygen $=5.060 \mathrm{gm}$.

Residual analyses show: (1) no change in $\mathrm{CO}_{2}$ of air but (2) amount of $\mathrm{O}_{2}$ is less. $(12.5258-12.5128=.01301 .=.0186 \mathrm{gm}$. $)$ This shows that flame 
used a little more $\mathrm{O}_{2}$ than was admitted; therefore, $5.060+.0186=5.079 \mathrm{gm}$. $\mathrm{O}_{2}$ actually used. Reducing weights to volume:

$$
\begin{aligned}
& \text { log. weight } \mathrm{CO}_{2}(4.850 \mathrm{gm} \text {. })=68574 \\
& \text { log. weight to vol. }\left(\mathrm{CO}_{2}\right) \quad 70680 \\
& \text { log. weight } \mathrm{O}_{2}(5.079)=70578 \\
& \text { log. weight vol. }\left(\mathrm{O}_{2}\right)=84496 \\
& \text { R. Q. }=\frac{\text { Vol. } \mathrm{CO}_{2}}{\text { Vol. } \mathrm{O}_{2}}=\frac{2.469}{3.554}=.695
\end{aligned}
$$

Second period from $5: 52$ to $6: 52$.

At 6:52 residual analysis.

5 liters air contain $0.0166 \mathrm{gm} . \mathrm{CO}_{2}$ and $.0114 \mathrm{gm} . \mathrm{H}_{2} \mathrm{O}$

67 liters air contain $0.222 \mathrm{gm} . \mathrm{CO}_{2}(=0.113 \mathrm{l}$.

66 liters air contain 0.150 gm. $\mathrm{H}_{2} \mathrm{O}(=0.187$ i.)

$$
0.113+0.187=0.300 \mathrm{l} . \mathrm{CO}_{2} \text { and } \mathrm{H}_{2} \mathrm{O} \text {. }
$$

Temperature $28.4 \mathrm{C}$. Barometer $765.3 \mathrm{~mm}$.

$$
\begin{array}{ll}
\log .69= & \\
\log . \frac{1}{1+00367\left(28.4^{\circ}\right)}= & 95695 \\
\log \cdot \frac{765.3}{760}= & 00302 \\
& 79882=
\end{array}
$$

Subtracting $\mathrm{N}_{2}$ with which exp'm't started 50.1032

"Respiratory Exchange" second period.

$$
\overline{12.5208} 1 . \mathrm{O}_{2}
$$

Gain in weight of $\mathrm{CO}_{2}$ absorbers $4.968 \mathrm{gm}$.

Residual analyses show that $\mathrm{CO}_{2}$ in air was less at 6.52 than at

$$
5.52(0.238-0.222=.016) 4.968 \mathrm{gm} .
$$

Actual amount of $\mathrm{CO}_{2}$ given off $=\frac{.016}{4.952} \mathrm{gm} .=(2.521 \mathrm{l}$.)

Loss in weight of $\mathrm{O}_{2}$ cylinder.... $5.500 \mathrm{gm}$.

Less 0.6 per cent. for argon....... .033

$$
\overline{5.467} \mathrm{gm} \text {. }
$$

Residual analyses show more $\mathrm{O}_{2}$ in air at 6.52 than at 5.52

$$
12.5208-12.5128=.01801 .=.026 \mathrm{gm} \text {. }
$$

$$
5.467
$$

Actual amount of $\mathrm{O}_{2}$ used by flame $=\frac{.026}{5.441} \mathrm{gm} .=(3.807$ 1.)

$$
\text { R. Q. }=\frac{2.521}{3.807}=.662
$$

First period.. .695

Second period .662

Average ... $\overline{.677}$ Theory .666; error 1.6 per cent.

Table 2 gives the respiratory quotients obtained with the alcohol lamp for all the experiments between June 1, 1913, and July 1, 1914, on which all corrections could be made: 
TABLE 2.-Respiratory Quotients for Experiments Between June 1, 1913, AND JULy 1, 1914

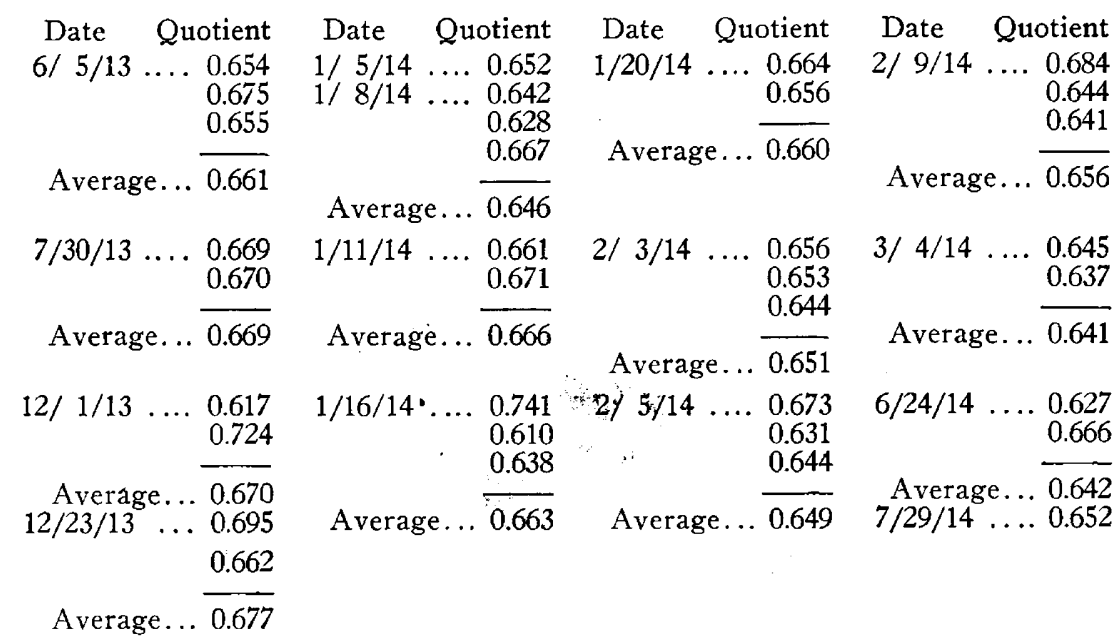

It will be seen that a perfectly theoretical result not infrequently occurs in a single period, but that often one period shows a high and the succeeding one a low restlt, the mean being very near to the theoretical value. This in most instances is due to a rise or fall of temperature near the end of the first period. The average error for all of the daily averages is 1.8 per cent.

\section{CONTROLS WITH DIABETIC DOGS}

Dogs completely under the influence of phlorhizin or deprived of the pancreas have a total incapacity to oxidize glucose. This results in a respiratory quotient ${ }^{8}$ which varies but slightly from 0.69 . The diabetic dog, therefore, is a suitable subject for controlling the efficiency of a respiration apparatus of this type. The apparatus here described has been used in the study of certain problems in connection with pancreatic diabetes. ${ }^{9}$ The following are examples of the quotients obtained on dogs which were known from the relation of dextrose to nitrogen in the urine to be completely diabetic:

$\begin{array}{lcrrrr}\text { Dog VI. July } & 9,1913 . & \text { R. Q. } & 11.27-12.27 & .68 \\ 12.27-1.27 & .68 \\ \text { Dog C. } & \text { July } & 23,1914 . & \text { R. Q. } & 3.42-4.27 & .69 \\ & & & & 4.27-5.13 & .68 \\ & & & & 8.03-8.49 & .68 \\ \text { Dog E. } & \text { Aug. } & 4,1914 . & \text { R. Q. } & 5.27-6.27 & .683 \\ 8.27-9.27 & .685\end{array}$

8. With the depancreatized $\operatorname{dog}$ this level is not invariably reached until about the fourth or fifth day after operation.. Cf. Verzár: Biochem. Ztschr., 1914, xlxvi, 75.

9. Murlin, Edelmann and Kramer: Jour. Biol. Chem., 1913, xvi, 79 and Kramer and Murlin; ibid., 1914. 
Animal experiments of this kind furnish a better control of the efficiency of the apparatus for work with infants than does the alcohol flame, for the reason that both the chemical and the physical properties of the air are more nearly like those of an experiment with the child. As a matter of course, the entire air circuit is thoroughly sterilized by means of formaldehyd, circulated by means of the blower, before the apparatus is used with the infant.

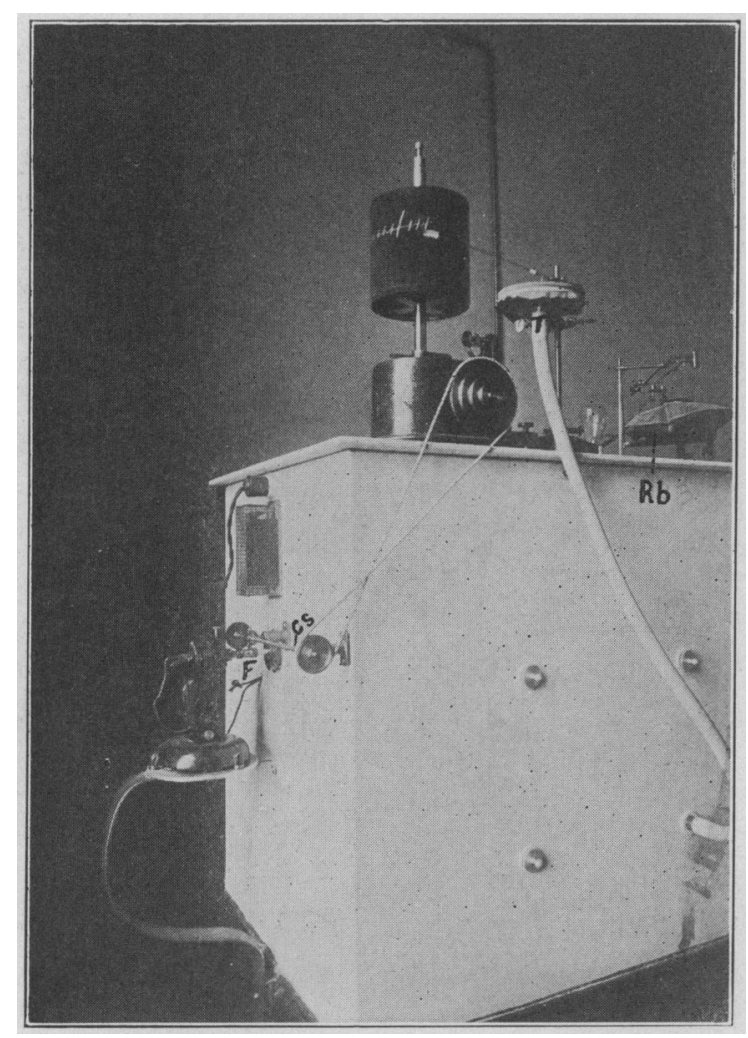

Fig. 6.-View of the rear end of the incubator showing fan motor $(F)$; counter shaft $(C S)$ for driving kymograph, and large recording tambour $(T)$ for registering movements of the infant. $R b$, rubber bag for equalizing tension and regulating flow of oxygen into the circuit.

\section{OXYGEN BLANK}

This form of control, introduced by Williams, ${ }^{10}$ has been found useful as a check on the gas analysis. It consists in sealing up the chamber, starting the blower and taking off a sample of air just as in starting a period for an alcohol check, but: without a subject or lamp in the chamber. If the air which is thus closed in the circuit is some-

10. Williams: Jour. Biol. Chem., 1912, xii, 346. 
what moist, the water absorbers will remove the water and its place will be taken by oxygen from the cylinder. The same would happen if the temperature were permitted to fall. At the end of an hour another sample of air is taken for analysis, and after the corrections for temperature and pressure are made, the amount of water lost from the air, as indicated by the residual analyses, should be equal to the amount of oxygen which has been lost from the cylinder. In such a check conducted on June 22, 1914, the amount of oxygen admitted was 0.346 liter in one hour. The air lost 0.411 liter of water; the carbon dioxid did not change. The temperature had risen $0.2^{\circ}$ and

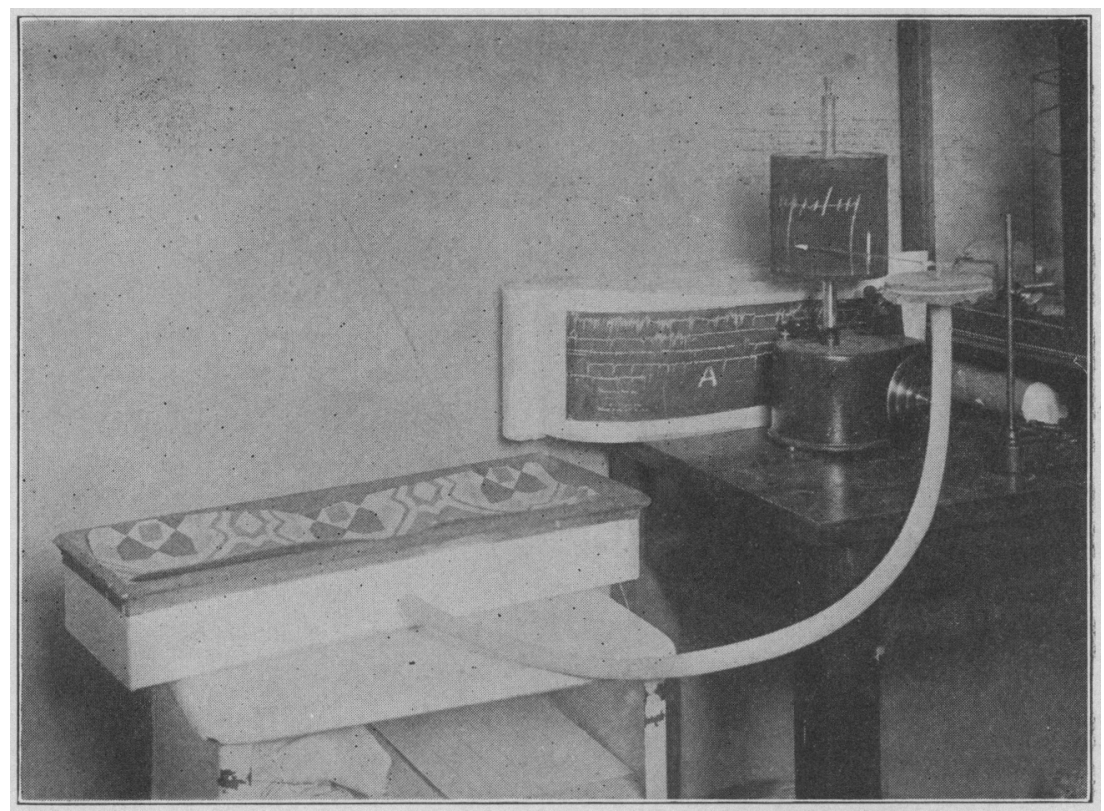

Fig. 7.-Rubber bed used for recording motions of the child, showing the wide tube and large tambour necessary for quick transmission. The character of the tracings obtained is seen in the open book (A).

the barometer had remained stationary. The temperature change caused an expansion of 0.056 liter in the entire system which would serve to keep out that much oxygen. Hence $(0.346+.056=) .4021$. of oxygen, with no temperature change, would have been admitted to replace a (calculated) shinkage of 0.411 liter.

REGISTRATION OF MUSCULAR ACTIVITY OF INFANT

The fan motor can be utilized for driving a kymograph situated on top of the incubator (Fig. 6). A small counter-shaft (cs) driven by a worm gear working on the axle of the fan carries a small pulley at 
its outer end and this connects directly with the driving pulley of the kymograph.

For recording the actual motions of the infant several devices have been employed. ${ }^{11}$ One of them employed with new-born infants consists of two large tambours connected by wide rubber tubing (Fig. 7). One of these tambours is the infant's bed while in the respiration chamber. The other ( 6 inches in diameter) carries a lever which writes directly on the smoked paper.

The bed consists of a galvanized iron box (10 by 22 by $61 \mathrm{~cm}$.) covered with a piece of rubber sheeting. The rim of the box over which the sheeting fits is so made that the rubber comes in contact successively with two surfaces, each about $1 \mathrm{~cm}$. broad, before it reaches the outside surface of the box itself. The corners, of course, are all rounded. An air-tight joint was secured by means of thick alcohol shellac. After the joint had been coated heavily with the shellac, the box was left for some days inverted on the rubber surface and weighted. Then the second surface was treated in the same way and the rubber tied firmly with a heavy cord. After several days' drying it was found to be air-tight. As a receiving plate for the infant's body a piece of linoleum of appropriate size was cemented to the upper surface of the rubber sheeting. A light blanket placed over this made a very comfortable bed.

Every motion of the infant was transmitted as an air wave to the recording tambour. In fact, the only objection to the device was its extreme sensitiveness. Even the pulsations of the air caused by the ventilating blower were recorded (Fig. $7 \mathrm{~A}$ ). With older infants ${ }^{12}$ the bed was discarded and the muscular motions were recorded by means of a cuff on the leg and a very flexible pneumograph placed about the chest.

11. See following papers.

12. See paper by Murlin and Hoobler to appear in this journal shortly. 